\title{
Effect of paiteling on human papillomavirus infection of the cervix
}

\author{
PINGPING TAO $^{1 *}$, WEIPING ZHENG ${ }^{2 *}$, XIAOHUA MENG ${ }^{2}$, JUNXIA CHEN $^{2}$, \\ AIJING SUN $^{3}$, QINGHE SHOU ${ }^{2}$, YUNGEN WANG ${ }^{2}$ and BINLIE YANG ${ }^{1}$ \\ ${ }^{1}$ Department of Obstetrics and Gynecology, Shanghai Pudong New Area People's Hospital, \\ Shanghai 201299; ${ }^{2}$ Department of Gynaecology, Shaoxing People's Hospital; ${ }^{3}$ Department of Pathology, \\ Shaoxing Hospital of Zhejiang University, Shaoxing, Zhejiang 312000, P.R. China
}

Received July 27, 2017; Accepted October 12, 2017

DOI: $10.3892 / \mathrm{mco} .2017 .1454$

\begin{abstract}
The aim of the present study was to investigate the effect of the traditional Chinese medicine paiteling on the outcome of high-risk human papillomavirus (HR-HPV) infection of the cervix. A total of 321 patients were enrolled in this study and HPV subtypes were determined by the Hybribio HPV genotyping system. The patients were divided into the loop electrosurgical excision procedure (LEEP; $\mathrm{n}=82$ ) and non-LEEP $(n=239)$ groups, according to the cervical intraepithelial neoplasia classification. These two groups were further subdivided into the drug (paiteling) and control subgroups. Thin-prep cytology and HR-HPV tests were performed every 3 months for 1 year. In the non-LEEP group, the negative conversion rate of HR-HPV and the regression rate of the cervical lesions in drug subgroup were significantly higher compared with those in the control subgroup. In the LEEP group, the seroconversion rate of the drug subgroup, but not the regression rate of the lesions, was significantly higher compared with that in the control subgroup. The seroconversion rate of HPV16-infected patients at 12 months was $85.7 \%$, whereas it reached $100 \%$ in all other HPV subtypes. Therefore, paiteling may accelerate the clearance of HPV infection and the regression of cervical lesions.
\end{abstract}

\section{Introduction}

Cervical cancer has one of the highest incidences among malignant tumors in women worldwide (1). A direct cause

Correspondence to: Dr Binlie Yang, Department of Obstetrics and Gynecology, Shanghai Pudong New Area People's Hospital, 490 Chuanhuan South Road, Shanghai 201299, P.R. China

E-mail: qwertasdfg_2015@163.com

Dr Yungen Wang, Department of Gynaecology, Shaoxing People's Hospital, 575 Pingjiang Road, Shaoxing, Zhejiang 312000, P.R. China

E-mail: abc_45d@163.com

${ }^{*}$ Contributed equally

Key words: papillomavirus infections, paiteling, outcome, clearance rate, human papillomavirus subtypes of cervical cancer is persistent infection by high-risk human papillomavirus (HR-HPV). HR-HPV infection may lead to integration of viral DNA into the host cell DNA, resulting in abnormal proliferation, cell deformation and, eventually, cervical intraepithelial neoplasia (CIN) (2). CIN may further progress into carcinoma in situ and invasive cancer. It is believed that different subtypes of HPV have a distinct virulence for the cervical epithelium (3). Cervical cells may become atypic following integration of the viral DNA into the host cell DNA, eventually developing into cervical cancer.

The probability of genital HPV infection within a woman's lifespan is $>75 \%$. Most infections are transient and clear up without any intervention within a few months to 2 years after the infection, while only a few are persistent (4). Due to the differences in host and environmental factors, the natural progression of HPV infection varies significantly among diverse populations. As a result, it is difficult to identify which HPV-infected patients will eventually develop cervical cancer. At present, follow-up or local physical therapy (including laser ablation, cryosurgery and microwave ablation) are applied to patients with CIN 1, while loop electrosurgical excision procedure (LEEP) and cold knife conization are applied to patients with $\mathrm{CIN} \geq 2$. However, these methods have the disadvantages of incomplete treatment and recurrence. There is also no proper treatment for patients with subclinical infection who are persistently HPV-positive and for those who are persistently HPV-positive following treatment for cervical CIN.

For the abovementioned reasons, we aimed to apply the Chinese medicine paiteling to treat HR-HPV subclinical infection and CIN, as paiteling has been reported to have successfully treated genital warts (5). Paiteling selectively destroys cancer cell membranes, including cytoplasmic and mitochondrial membranes, thereby suppressing cancer cell proliferation by its cytotoxic action, ultimately leading to tumor cell degeneration and necrosis; it may also destroy intracellular parasitic virus, and inhibit and clear HPV infection (6).

In the present study, patients with subclinical HR-HPV infection or CIN, with or without LEEP therapy, were selected to test the effects of paiteling on clearing HPV.

\section{Patients and methods}

Patient data. Patients confirmed to be HR-HPV-positive with the Hybribio HPV Genotyping system (Hybribio 
Biotechnology Co. Ltd., Chaozhou, China) between January, 2011 and June, 2013 at the Shanghai Pudong New Area People's Hospital (Shanghai, China) were considered as eligible candidates. These patients were then examined by liquid-based cervical cytology, colposcopy and histopathological examination. Patients with one of the following symptoms were finally selected: Normal or chronic cervicitis; condyloma-like changes, with or without chronic cervicitis; CIN 1, with or without condyloma-like changes; $C I N \geq 2$, without invasive carcinoma. The inclusion criteria were as follows: Cervical pathology in line with the aforementioned conditions; women of childbearing age; HR-HPV positive; no previous history of cervical cancer or precancerous lesions; no previous history of cervical physical therapy or surgery. The exclusion criteria were pregnancy or lactation.

Prior written informed content was obtained from each patient. This study was approved by the Ethics Committee of the Shanghai Pudong New Area People's Hospital.

Grouping. A total of 321 patients were enrolled in this study. The patients were divided into the LEEP $(n=82)$ and non-LEEP $(n=239)$ groups, according to the CIN classification. Patients in each group were randomly assigned into the drug and control subgroups. A total of 239 cases were included in the non-LEEP group, with a mean age of 36.07 years, with 109 cases in the drug and 130 cases in the control subgroups.

The LEEP group included HR-HPV-positive patients with a biopsy outcome of CIN 2 (equivalent to moderate cervical dysplasia) or CIN 3 (equivalent to severe cervical dysplasia and carcinoma in situ), as well as a few CIN 1 patients who wished to undergo surgery. The non-LEEP group included HR-HPV-positive patients with a biopsy outcome of CIN $<2$, as well as a few CIN 2 patients who had not given birth and wished to undergo conservative therapy. The pathological outcomes of the patients were usually chronic cervicitis, condyloma-like changes with or without chronic cervicitis, CIN 1 with or without condyloma-like changes, CIN 1 and CIN 2.

Follow-up was performed for the control subgroup, while the drug subgroup treated with paiteling was tested for HR-HPV with the Thin-prep cytology test (TCT) every 3 months for 1 year. The HPV seroconversion rates and the regression rates of the cervical lesions were compared between the control and drug subgroups at different time points, and the natural seroconversion rate of HPV was analyzed.

Hybribio HPV detection. The Hybribio HPV Genotyping system was used for identifying $21 \mathrm{HPV}$ subtypes of exfoliative cells within the cervical canal. The detected HPV subtypes in this study included HPV16, 18, 31, 33, 35, 45, 51, 52, 53, 56, 58, 59, 66, 68 and CP8304. The presence of any of these HPV subtypes or multiple infections was considered as HR-HPV infection.

Cytological examination. TCT was used for cervical cytology. The specimens were collected by a TCT special brush. Clinical diagnosis was based on the 2001 revised descriptive diagnosis (The Bethesda System) (7). Cellular morphology greater than or equal to a result of atypical cells of undetermined significance (ASC-US) was defined as an abnormality.
Colposcopy examination. For HR-HPV-positive patients, provided they consented to further investigation, colposcopy was performed regardless of the cytological status (normal or abnormal). A Leica CH 9435 photoelectric vaginoscope (Leica Microsystems, Wetzlar, Germany) was used for colposcopic examination. The cervical color, blood vessels and white spots were observed. Following application of a 5\% acetic acid solution coat on the surface of the cervix, dynamic changes of the lesion boundary, color and vascularity were observed. The distribution and status of different iodine-stained regions were observed following application of iodine solution to the cervical surface.

Histopathological examination. The specimens collected under vaginoscopic guidance were subjected to histopathological examination. The specimens were routinely collected from 4 points, namely at the 3, 6, 9 and 12 o'clock positions of the transitional zone in cases without visible abnormalities; if abnormalities were present, multiple points from the abnormal area were biopsied.

LEEP. For the surgery, the iodine-colored area to an outer zone of $\sim 3-5 \mathrm{~mm}$ from the lesion was removed following coating with Lugol's solution. Mixed cutting mode was applied, with an electrode power of $50 \mathrm{~W}$. If the iodine-negative area was close to the vaginal vault and was difficult to access, a larger circumferential area was resected. The removed lesions were subjected to pathological examination.

Paiteling treatment. Paiteling (Beijing Paderborn Biological Technology Co. Ltd., Beijing, China) was applied 3 days after the end of menstruation. Starting on the 3rd day after the end of menstruation, the drug was applied on days 1-4, 8-11 and 15-18, with a total of 12 applications. At 12 days after the end of the second menstruation, irrigation was performed with 1:50 diluted liquid once a day, for $15 \mathrm{~min}$ per time. The treatment was discontinued upon menstruation. Bathing and sexual intercourse were prohibited during the treatment period.

Outcome evaluation. Negative conversion of HR-HPV was determined according to the results of the Hybribio HPV Genotyping system, regardless of the outcome of the cytological examination. In addition, all the subtypes of multiple infections should be converted to negative. Cervical lesion regression was determined by the combination of cytological examination and pathological diagnosis. If both cytological and histopathological results were available, the regression outcome was determined according to the histopathological results, while the cytopathological results were considered as the standard if they were the only results available. The histopathological criteria were as follows: Disease progression, the pathological results were upgraded when compared with those on enrollment; continuous lesions, the pathological results remained unchanged; and lesion regression, the pathological results were downgraded compared with those on enrollment. The cytopathological criteria were as follows: Disease progression, the TCT results were upgraded; continuous lesions, the TCT results remained unchanged; and lesion regression, the TCT results were normal. The results were 
Table I. Cytological and pathological results in the drug and control subgroups of the non-LEEP group.

\begin{tabular}{|c|c|c|c|c|c|}
\hline \multirow[b]{2}{*}{ Cytological results } & \multicolumn{2}{|c|}{ Subgroups } & \multirow[b]{2}{*}{ Pathological results } & \multicolumn{2}{|c|}{ Subgroups } \\
\hline & Control & Drug & & Control & Drug \\
\hline $\operatorname{ASC}(n=92)$ & 51 & 41 & Chronic cervicitis $(n=52)$ & 26 & 26 \\
\hline HSIL (n=3) & 2 & 1 & Condyloma-like changes with chronic cervicitis $(n=60)$ & 30 & 30 \\
\hline LSIL (n=76) & 40 & 36 & Condyloma-like changes $(\mathrm{n}=52)$ & 26 & 26 \\
\hline NILM $(n=68)$ & 37 & 31 & CIN 1 with condylomalike changes $(n=26)$ & 13 & 13 \\
\hline \multirow[t]{3}{*}{ Total $(n=266)$} & 148 & 118 & CIN 1 and CIN 1-2 $(n=14)$ & 7 & 7 \\
\hline & & & CIN $2(n=14)$ & 7 & 7 \\
\hline & & & Total $(n=218)$ & 109 & 109 \\
\hline
\end{tabular}

LEEP, loop electrosurgical excision procedure; ASC, atypical squamous cells; HSIL, highgrade squamous intraepithelial lesion; LSIL, lowgrade squamous intraepithelial lesion; NILM, negative for intraepithelial lesion and malignancy; CIN, cervical intraepithelial neoplasia.
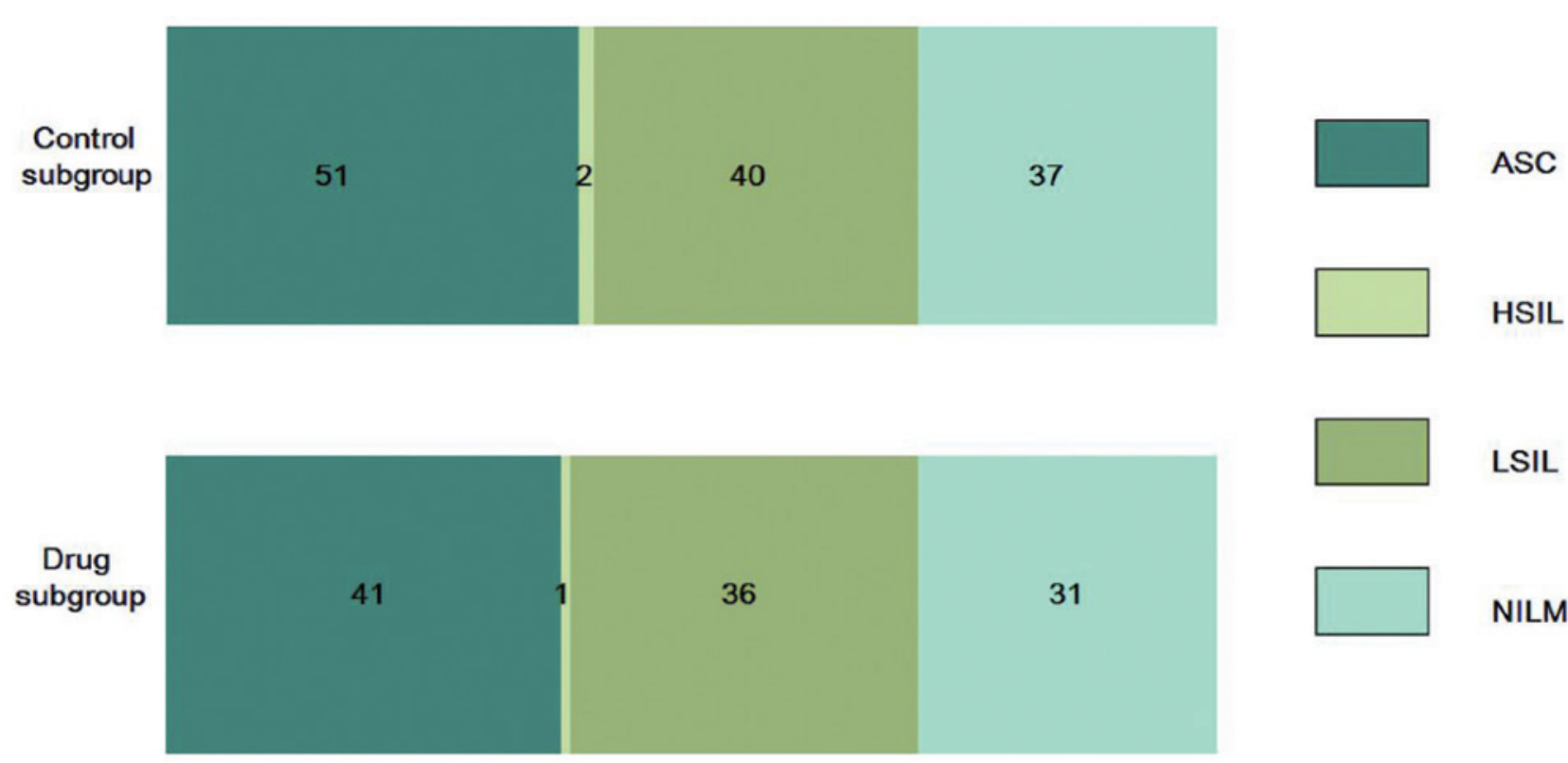

LSIL

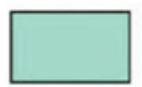

NILM

Figure 1. Cytological diagnosis in the drug and control subgroups of the non-LEEP group. The numbers represent the cases per category. LEEP, loop electrosurgical excision procedure; ASC, atypical squamous cells; HSIL, high-grade squamous intraepithelial lesion; LSIL, low-grade squamous intraepithelial lesion; NILM, negative for intraepithelial lesion and malignancy.

evaluated at the 6-, 9- and 12-month time point. For patients who remained HPV-positive, another treatment course was performed according to the wishes of patients, until HPV was negative. If HPV remained positive after 12 months of paiteling treatment and follow-up, the treatment was considered ineffective.

Statistical analysis. All the statistical analyses were performed using SPSS software for Windows, version 10.0 (SPSS Inc., Chicago, IL, USA) and P-values $<0.05$ were considered to indicate statistically significant differences. The possibility of the natural seroconversion rate of HR-HPV was expressed as a percentage. The time to seroconversion indicated mean usage times. The seroconversion rates of HR-HPV and the regression rates of the cervical lesions were compared between subgroups using the Chi-squared and exact tests.

\section{Results}

Effects of paiteling in the non-LEEP group. To investigate the effects of paiteling in the non-LEEP group, HPV negative conversion and cervical lesion regression at different time points were compared. The cytological and pathological results of both groups are shown in Table I. There were no significant differences in the cytological results and pathological diagnosis between the drug and the control subgroups (Fig. 1). In the drug subgroup, 1 patient discontinued treatment due to vaginitis, 3 cases were lost and 2 cases proceeded to undergo LEEP due to an HPV-positive status at 9 months. In the control subgroup, 4 cases were lost at 6 months, 10 cases were lost at 9 months and 15 cases were lost at 12 months.

The natural seroconversion rate of HPV was analyzed by comparing the seroconversion rate of HR-HPV at different time points with that of the control subgroup. As shown in 
Table II. Comparison of seroconversion rates in the non-LEEP group.

\begin{tabular}{|c|c|c|c|c|c|c|c|c|}
\hline \multirow[b]{2}{*}{$\begin{array}{l}\text { Follow-up } \\
\text { time, months }\end{array}$} & \multicolumn{3}{|c|}{ Paiteling group } & \multicolumn{3}{|c|}{ Control group } & \multirow[b]{2}{*}{$\chi^{2}$} & \multirow[b]{2}{*}{ P-value } \\
\hline & $\begin{array}{l}\text { Total } \\
\text { cases }\end{array}$ & $\begin{array}{c}\text { Negative } \\
\text { cases }\end{array}$ & $\begin{array}{c}\text { Negative } \\
\text { conversion }(\%)\end{array}$ & $\begin{array}{l}\text { Total } \\
\text { cases }\end{array}$ & $\begin{array}{l}\text { Negative } \\
\text { cases }\end{array}$ & $\begin{array}{c}\text { Negative } \\
\text { conversion (\%) }\end{array}$ & & \\
\hline 6 & 105 & 88 & 83.9 & 126 & 35 & 27.8 & 66.99 & $<0.01$ \\
\hline 9 & 105 & 94 & 89.5 & 120 & 46 & 38.3 & 60.27 & $<0.01$ \\
\hline 12 & 103 & 98 & 95.2 & 115 & 82 & 71.3 & 19.83 & $<0.01$ \\
\hline
\end{tabular}

LEEP, loop electrosurgical excision procedure.

Table III. Comparison of regression rates in the non-LEEP group.

\begin{tabular}{|c|c|c|c|c|c|c|c|c|}
\hline \multirow[b]{2}{*}{$\begin{array}{l}\text { Follow-up } \\
\text { time, months }\end{array}$} & \multicolumn{3}{|c|}{ Paiteling group } & \multicolumn{3}{|c|}{ Control group } & \multirow[b]{2}{*}{$\chi^{2}$} & \multirow[b]{2}{*}{ P-value } \\
\hline & $\begin{array}{l}\text { Total } \\
\text { cases }\end{array}$ & $\begin{array}{l}\text { Regression } \\
\text { number }\end{array}$ & $\begin{array}{l}\text { Regression } \\
\text { rate }(\%)\end{array}$ & $\begin{array}{l}\text { Total } \\
\text { cases }\end{array}$ & $\begin{array}{c}\text { Regression } \\
\text { number }\end{array}$ & $\begin{array}{c}\text { Regression } \\
\text { rate }(\%)\end{array}$ & & \\
\hline 6 & 105 & 89 & 84.8 & 126 & 38 & 30.2 & 66.80 & $<0.01$ \\
\hline 9 & 105 & 90 & 85.7 & 120 & 56 & 46.7 & 35.78 & $<0.01$ \\
\hline 12 & 103 & 94 & 91.3 & 115 & 64 & 55.7 & 31.05 & $<0.01$ \\
\hline
\end{tabular}

LEEP, loop electrosurgical excision procedure.

Table II, the natural seroconversion rates at 6,9 and 12 months were $27.8,38.3$ and $71.3 \%$, respectively.

As shown in Table III, the seroconversion rates were significantly higher compared with those in the control subgroup $(\mathrm{P}<0.01)$. The regression rates of the cervical lesions in the drug subgroup at 6,9 and 12 months were $84.8,85.7$ and $91.3 \%$, respectively, which were also significantly higher $(\mathrm{P}<0.01)$ compared with those in the control subgroup $(30.2$, 46.7 and $55.7 \%$, respectively).

Therefore, the results suggested that paiteling was effective against HR-HPV infection and it is possible that it accelerated the regression of the lesions.

Effects of paiteling in the LEEP group. To identify the effects of paiteling in the LEEP group, the seroconversion rates and regression rates in the subgroups were calculated. The cytological and pathological results in both groups are summarized in Table IV. The pathological diagnoses were similar between the two subgroups (Fig. 2). In the drug subgroup, 2 cases were lost after being followed up for 6 months. In the control subgroup, 4 cases further underwent cold knife conization due to positive surgical margins in the pathological report following LEEP, and abnormal TCT and/or HPV-positive status at the 6- and 9-month follow-up. One patient, who had negative surgical margins but was HPV-positive, atypical squamous cells-cannot exclude high-grade squamous intraepithelial lesion (ASC-H) on TCT and emotional stress, also underwent cold knife conization. The abovementioned 5 cases were excluded from further analysis.

The seroconversion rates of the drug subgroup at 6,9 and 12 months were $83.3,90.0$ and $95.0 \%$, respectively, which
Table IV. Cytological results in the drug and control subgroups of the LEEP group.

\begin{tabular}{lccr}
\hline & \multicolumn{3}{c}{ Subgroups } \\
\cline { 2 - 4 } Cytological results & Control & Drug & Total \\
\hline CIN 1 & 3 & 4 & 92 \\
CIN 2 & 17 & 16 & 3 \\
CIN 3 & 20 & 22 & 76 \\
Total & 148 & 118 & 266 \\
\hline
\end{tabular}

LEEP, loop electrosurgical excision procedure; CIN, cervical intraepithelial neoplasia.

were significantly higher $(\mathrm{P}<0.01)$ compared with those of the control subgroup (60.0, 71.4 and $80.0 \%$, respectively; Table IV). This result indicated that LEEP surgery removed the majority of the cervical lesions at the time of HPV clearance, and paiteling accelerated the clearance of residual HPV virus.

As shown in Table IV, the regression rates of the cervical lesions in the drug subgroup at 6,9 and 12 months were 92.2, 92.5 and $92.5 \%$, respectively, while they were $77.5,85.7$ and $88.6 \%$, respectively, in the control subgroup. The regression rate differed significantly between the two subgroups at 6 months. Among the patients, 2 cases, including one ASC-H and one ASCUS case, were converted to HPV-negative and normal TCT at 6 months, but exhibited HPV positivity at 9 months. Therefore, 

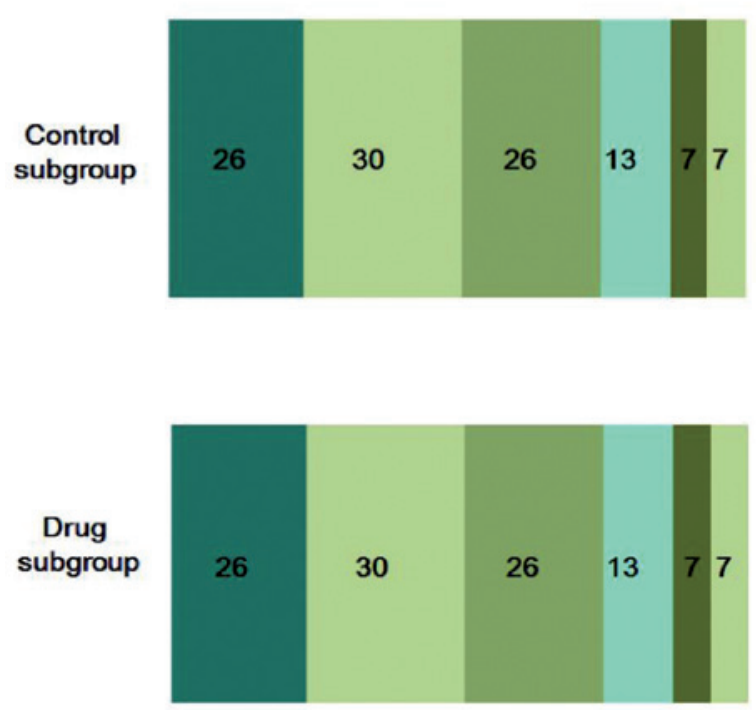

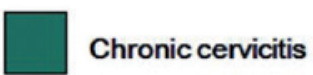

Condyloma-like changes with chronic cervicitis

Condyloma-like changes

CINI with condyloma-like changes

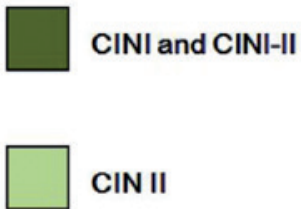

Figure 2. Histopathological diagnosis in the drug and control subgroups of the non-LEEP group. The numbers represent the cases per category. LEEP, loop electrosurgical excision procedure; CIN, cervical intraepithelial neoplasia.

the possibility of re-infection and the emergence of disease cannot be ruled out. In conclusion, the results demonstrated that paiteling may significantly increase the regression rate.

Correlation between HPV subtypes and the effects of paiteling. In order to determine whether the effects of paiteling are associated with HPV subtype, the seroconversion rates were compared among the drug subgroups. The top 5 HPV subtypes were HPV16 ( $n=38)$, HPV52 ( $n=20), \operatorname{HPV} 58(n=16)$, HPV53 $(n=10)$ and HPV39 $(n=9)$. The numbers of seroconversion cases (rates) of HPV16 at 6, 9 and 12 months were $25(67.7 \%)$, $29(78.4 \%)$ and $30(85.7 \%)$, respectively. In contrast to HPV16, the remaining subtypes all reached $100 \%$ at 12 months, while there were cases remaining HPV-positive at 6 and 9 months. However, 5 cases were lost and it was possible that the lost cases did not convert to negative (Fig. 3). During the follow-up, $\sim 5.3-25 \%$ cases infected with HPV52, 58, 33 or 39 had not converted to negative at 6 and 9 months, whereas they had all become negative at 12 months. The seroconversion rates of HPV39, 56, 66, 68, 31, CP8304 and 45 were all 100\% when reviewed the first time after applying the drug, and the HPV-negative status was maintained until the end of follow-up (Table VII). Therefore, the effects of paiteling on different HPV subtypes varied significantly.

\section{Discussion}

The majority CIN 1 or HPV-infected cases may be reversed naturally without any intervention; however, some will progress to advanced grades (8). In a previous study, 817 HR-HPV-positive Korean patients were followed up for 24 months (9). It was found that HPV was cleared in 648/817 (79.3\%) cases within 24 months. Of the remaining 169 cases, $66(39.1 \%)$ progressed to $\mathrm{CIN} \geq 2$. Bae et al (10) reported that the possibility of cytological abnormalities, CIN and high-grade CIN in patients with persistent HR-HPV infection for 24 months was $38.2,21.7$ and $8.5 \%$, respectively. In the present study, $130 \mathrm{HR}-\mathrm{HPV}$-infected patients were followed up and the seroconversion rates, without any intervention, at 6,9 and 12 months were $27.8,38.3$ and $71.3 \%$, respectively. This finding was similar to the previous study (9), suggesting that $28.7 \%$ of the cases were HPV-positive at 12 months. These results prompted us to investigate the reasons for the different outcomes following HPV infection.

It has been demonstrated that the clearance of HPV mainly depends on HPV subtypes, and high-risk HPV is associated with lower clearance rates. HR-HPV persistence is also affected by other factors, such as the body's immunity, while HPV clearance has been associated with ethnicity and the presence of chlamydia infection. No significant correlation with marital status or the number of sexual partners was identified (11). It has been reported that age, number of sexual partners, HR-HPV viral load, integrated state and the results of cytology and pathology may be used to predict the progression and regression of HPV infection and CIN 1. However, the results reported by different studies have been inconsistent, or even opposing (12-16). Kim et al suggested cytological results and viral load as useful indicators to predict viral clearance and the progression of lesions (9).

There is currently no drug effectively blocking HPV infection, or used specifically for the treatment of CIN 1-2. As the pathogens associated with CIN and condylomata acuminata both belong to the HPV family, it would be of interest to test the effects of paiteling on HP-HPV infection and its consequences. It was reported that paiteling has been successfully used for the treatment of condylomata acuminata (17). In the present study, for patients in the non-LEEP group, it was found that the seroconversion and cervical lesion regression rates in the drug subgroup were significantly higher compared with those in the control subgroup. The results suggested that paiteling promoted the clearance of HR-HPV infection. A previous study also reported that more HR-HPV infection 
Table V. Comparison of seroconversion rates in the LEEP group.

\begin{tabular}{|c|c|c|c|c|c|c|c|c|}
\hline \multirow[b]{2}{*}{$\begin{array}{l}\text { Follow-up } \\
\text { time, months }\end{array}$} & \multicolumn{3}{|c|}{ Paiteling group } & \multicolumn{3}{|c|}{ Control group } & \multirow[b]{2}{*}{$\chi^{2}$} & \multirow[b]{2}{*}{ P-value } \\
\hline & $\begin{array}{l}\text { Total } \\
\text { cases }\end{array}$ & $\begin{array}{l}\text { Negative } \\
\text { cases }\end{array}$ & $\begin{array}{c}\text { Negative } \\
\text { conversion }(\%)\end{array}$ & $\begin{array}{l}\text { Total } \\
\text { cases }\end{array}$ & $\begin{array}{l}\text { Negative } \\
\text { cases }\end{array}$ & $\begin{array}{c}\text { Negative } \\
\text { conversion }(\%)\end{array}$ & & \\
\hline 6 & 42 & 35 & 83.3 & 40 & 24 & 60.0 & 0.035 & $<0.05$ \\
\hline 9 & 40 & 36 & 90.0 & 35 & 25 & 71.4 & 0.039 & $<0.05$ \\
\hline 12 & 40 & 38 & 95.0 & 35 & 28 & 80.0 & 0.046 & $<0.05$ \\
\hline
\end{tabular}

LEEP, loop electrosurgical excision procedure.

Table VI. Comparison of regression rates in the LEEP group.

\begin{tabular}{|c|c|c|c|c|c|c|c|c|}
\hline \multirow[b]{2}{*}{$\begin{array}{l}\text { Follow-up } \\
\text { time, months }\end{array}$} & \multicolumn{3}{|c|}{ Paiteling group } & \multicolumn{3}{|c|}{ Control group } & \multirow[b]{2}{*}{$\chi^{2}$} & \multirow[b]{2}{*}{ P-value } \\
\hline & $\begin{array}{l}\text { Total } \\
\text { cases }\end{array}$ & $\begin{array}{c}\text { Regression } \\
\text { number }\end{array}$ & $\begin{array}{c}\text { Regression } \\
\text { rate }(\%)\end{array}$ & $\begin{array}{l}\text { Total } \\
\text { cases }\end{array}$ & $\begin{array}{c}\text { Regression } \\
\text { number }\end{array}$ & $\begin{array}{c}\text { Regression } \\
\text { rate }(\%)\end{array}$ & & \\
\hline 6 & 42 & 39 & 92.9 & 40 & 31 & 77.5 & 3.87 & $<0.05$ \\
\hline 9 & 40 & 37 & 92.5 & 35 & 30 & 85.7 & 0.90 & $>0.05$ \\
\hline 12 & 40 & 37 & 92.5 & 35 & 31 & 88.6 & 0.34 & $>0.05$ \\
\hline
\end{tabular}

LEEP, loop electrosurgical excision procedure.
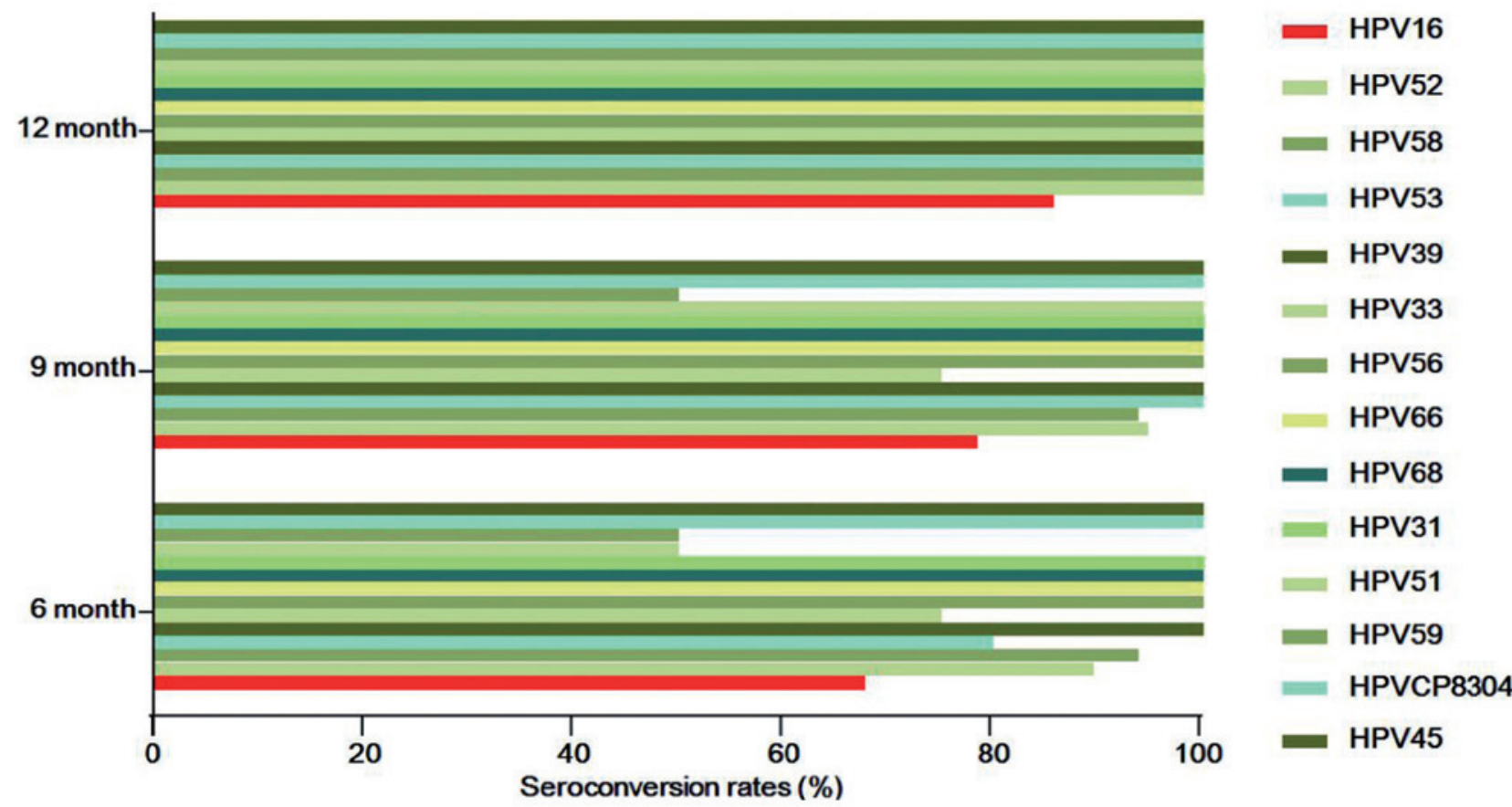

Figure 3. Seroconversion rates of HPV subtypes at different time points following paiteling treatment. HPV, human papillomavirus.

patients without LEEP converted to negative with paiteling treatment (18).

For patients in the LEEP group, the relevant literature reported that the seroconversion rates at 6 months after LEEP were 62.58-87.3\% (19,20). Alonso et al reported HR-HPV-positive rates of 35.3 and $27.1 \%$ at 6 and 12 months, respectively, without a statistically significant difference (21). Kim et al found that the rates of HR-HPV positivity at $3,6,9,12,18$ and 24 months were 45.6, 14.3, 6.3, 2.2, 1.5 and $1.1 \%$, respectively, in patients with a negative surgical margin following LEEP (22). These findings suggest that the majority of the lesions and the HPV infection are eliminated after LEEP; 
Table VII. Seroconversion rates of HPV subtypes at different time points following application of paiteling.

\begin{tabular}{|c|c|c|c|c|c|}
\hline \multirow[b]{2}{*}{ HPV subtype } & \multirow[b]{2}{*}{ Total cases } & \multicolumn{3}{|c|}{ Seroconversion cases, n (\%) } & \multirow[b]{2}{*}{ Note } \\
\hline & & 6 months & 9 months & 12 months & \\
\hline 16 & 38 & $25(67.7)$ & $29(78.4)$ & $30(85.7)$ & One lost; two lost at 12 months \\
\hline 52 & 20 & $17(89.5)$ & $18(94.7)$ & $19(100.0)$ & One lost \\
\hline 58 & 16 & $15(93.8)$ & $15(93.8)$ & $16(100.0)$ & \\
\hline 53 & 10 & $8(80.0)$ & $10(100.0)$ & $10(100.0)$ & \\
\hline 39 & 9 & $9(100.0)$ & $9(100.0)$ & $9(100.0)$ & \\
\hline 33 & 6 & $3(75.0)$ & $3(75.0)$ & $4(100.0)$ & $\begin{array}{l}\text { One lost; one with positive HPV merged with } \\
\text { HPV59 }\end{array}$ \\
\hline 56 & 5 & $5(100.0)$ & $5(100.0)$ & $5(100.0)$ & \\
\hline 66 & 5 & $5(100.0)$ & $5(100.0)$ & $5(100.0)$ & \\
\hline 68 & 5 & $5(100.0)$ & $5(100.0)$ & $5(100.0)$ & $\begin{array}{l}\text { Two merged with HPV } 16 \text { and remained positive; } \\
\text { one lost, while all others were negative }\end{array}$ \\
\hline 31 & 2 & $2(100.0)$ & $2(100.0)$ & $2(100.0)$ & \\
\hline 51 & 2 & $1(50.0)$ & $2(100.0)$ & $2(100.0)$ & $\begin{array}{l}\text { One with positive HPV at } 6 \text { months merged with } \\
\text { HPV } 52\end{array}$ \\
\hline 59 & 2 & $1(50.0)$ & $1(50.0)$ & $2(100.0)$ & \\
\hline CP8304 & 2 & $2(100.0)$ & $2(100.0)$ & $2(100.0)$ & \\
\hline 45 & 1 & $1(100.0)$ & $1(100.0)$ & $1(100.0)$ & \\
\hline
\end{tabular}

The HPV subtypes were sorted according to the number of infected patients in this study, from large to small, and multiple infections were counted repeatedly. The seroconversion rate of HR-HPV was determined according to the results of HPV genotyping, regardless of the outcomes of cytological examination. HPV, human papillomavirus.

however, there may still remain residual HPV and cervical lesions. More importantly, the clearance of HR-HPV after surgery directly affects residual lesions or recurrence (23).

Nagai et al believe that HPV positivity is a marker of residual or recurrent lesions (24). The residuality and/or recurrence of lesions is closely associated with HPV infection at 1 month after surgery and their likeliness increases with the prolongation of follow-up. Thus, early follow-up is necessary; additionally, close monitoring and treatment as required are recommended. We observed that the seroconversion and regression rates of the cervical lesions were higher in the drug subgroup compared with those in the control subgroup of the LEEP group. This finding was particularly significant at 6 months. Our results demonstrated that paiteling may accelerate HPV clearance. Guoqin et al reported that the improvement of the HPV load in the drug subgroup was significantly higher compared with that in the control subgroup (25). These results suggested that HR-HPV may be suppressed and cleared by paiteling, which provides a new approach to the treatment of residual HPV or the recurrence of subclinical infection following surgery in patients with advanced CIN lesions. However, the persistence of the effects of paiteling on HPV clearance requires an extended follow-up time and large clinical trials.

Different HPV subtypes exhibit variable pathogenicity for the cervical epithelium. HPV genotyping, as a complement to the traditional cytological examination, has been widely used, particularly for patients with indeterminate cytological diagnosis or for those comprising the population with critical and degenerative changes or persistent infection; it is also a crucial tool for predicting the cancerous tendency of cervical cells, enabling early detection, prevention and treatment of early cervical cancer. The Center for Disease Control and tumor prevention systems in the United States and Europe have strongly recommended that HPV genotyping is included in the screening for cervical cancer, and recommend multi-center cooperation to establish an effective early warning system. The present study used the Hybribio HPV Genotyping system, which has received the European CE certification and has been widely applied in clinical and scientific investigations. We observed that the seroconversion rate of HPV16-infected patients at 12 months was $85.7 \%$, while all other subtypes reached $100 \%$.

Different HPV subtypes exhibited distinct negative conversion rates with paiteling treatment. The correlation of the phenotype to the natural seroconversion rate has not yet been fully elucidated. Studies suggest that different HPV subtypes require different times to clear naturally. A meta-analysis based on 86 studies worldwide, including 100,000 women, demonstrated that the persistence of the HPV infection exhibited regional variation and subtype specificity. HPV16, 31, 33 and 52 are associated with high rates of persistent infection. The median time for HPV clearance is 9.8 months, whereas HPV16 requires 12.4 months (26). Dong et al reported seroconversion rates of $67.7,67.4$ and $43.5 \%$ for HPV16, 52 and 58, respectively, and the differences between HPV58 and each of the other two subtypes were found to be statistically significant (27). These findings suggest that the natural 
seroconversion rate should be considered when analyzing the correlation between HPV subtypes and the effects of paiteling.

In the present study, the beneficial effects of paiteling on patients with HR-HPV infection were demonstrated. Our results also suggested that the effects of paiteling were associated with HPV subtype, although the association cannot be precisely reflected due to the limited sample size. The assessment requires larger groups for analysis.

\section{Acknowledgements}

The present study was supported by the Key Scientific Research Project of Shaoxing City of Pudong Health and Family Planning Commission of Shanghai (grant no. PWZz2013-14), the Leader Training Plan of the Health Department Pudong New District of Shanghai (PWRd2013-09) and by grants from the Key Scientific Research Project of Shaoxing City of Zhejiang Province (2011A23017).

\section{References}

1. Ogunwale AN, Coleman MA, Sangi-Haghpeykar H, Valverde I, Montealegre J, Jibaja-Weiss M and Anderson ML: Assessment of factors impacting cervical cancer screening among low-income women living with HIV-AIDS. AIDS Care 28: 1-4, 2016.

2. Qiu AD, Wu EQ, Yu XH, Jiang CL, Jin YH, Wu YG, Chen Y, Chen Y, Shan YM, Zhang GN, et al: HPV prevalence, E6 sequence variation and physical state of HPV16 isolates from patients with cervical cancer in Sichuan, China. Gynecol Oncol 104: 77-85, 2007.

3. Ahmed HG, Bensumaidea SH and Ashankyty IM: Frequency of human papilloma virus (HPV) subtypes 31,33,35,39 and 45 among yemeni women with cervical cancer. Infect Agent Cancer 10: 29, 2015.

4. Ingles DJ, Pierce Campbell CM, Messina JA, Stoler MH, Lin HY, Fulp WJ, Abrahamsen M, Sirak BA, O'Keefe MT, Papenfuss M, et al: Human papillomavirus virus (HPV) genotype- and age-specific analyses of external genital lesions among men in the HPV infection in men (HIM) study. J Infect Dis 211: 1060-1067, 2015.

5. Yuan Q, Han J, Cong W, Ge Y, Ma D, Dai Z, Li Y and Bi X: Docetaxel-loaded solid lipid nanoparticles suppress breast cancer cells growth with reduced myelosuppression toxicity. Int J Nanomedicine 9: 4829-4846, 2014.

6. Parris GE: Hypothesis links emergence of chloroquine-resistant malaria and other intracellular pathogens and suggests a new strategy for treatment of diseases caused by intracellular parasites. Med Hypotheses 62: 354-357, 2004.

7. Kostova $\mathrm{P}$ and Zlatkov V: The Bethesda system: New revision of the terminology from 2001 year. Akush Ginekol (Sofiia) 43: 52-55, 2004 (In Bulgarian).

8. Bansal N, Wright JD, Cohen CJ and Herzog TJ: Natural history of established low grade cervical intraepithelial (CIN 1) lesions. Anticancer Res 28: 1763-1766, 2008.

9. Kim JW, Song SH, Jin CH, Lee JK, Lee NW and Lee KW: Factors affecting the clearance of high-risk human papillomavirus infection and the progression of cervical intraepithelial neoplasia. J Int Med Res 40: 486-496, 2012.

10. Bae J, Seo SS, Park YS, Dong SM, Kang S, Myung SK and Park SY: Natural history of persistent high-risk human papillomavirus infections in Korean women. Gynecol Oncol 115: 75-80, 2009.
11. Sycuro LK, Xi LF, Hughes JP, Feng Q, Winer RL, Lee SK, O'Reilly S, Kiviat NB and Koutsky LA: Persistence of genital human papillomavirus infection in a long-term follow-up study of female university students. J Infect Dis 198: 971-978, 2008.

12. Ye J, Cheng X, Chen X, Ye F, Lu W and Xie X: Short-term type-specific HPV persistence and its predictors in an asymptomatic general female population in Zhejiang, China. Int J Gynaecol Obstet 110: 217-222, 2010.

13. Fukuchi E, Sawaya GF, Chirenje M, Magure T, Tuveson J, Ma Y Shiboski S, Da Costa M, Palefsky J and Moscicki AB, et al: Cervical human papillomavirus incidence and persistence in a cohort of HIV-negative women in Zimbabwe. Sex Transm Dis 36: 305-311, 2009.

14. Munoz N, Hernandez-Suarez G, Mendez F, Molano M, Posso H, Moreno V, Murillo R, Ronderos M, Meijer C and Muñoz A; Instituto Nacional de Cancerología HPV Study Group: Persistence of HPV infection and risk of high-grade cervical intraepithelial neoplasia in a cohort of Colombian women. Br J Cancer 100: 1184-1190, 2009.

15. Guo YL, You K, Qiao J, Zhao YM, Liu CR and Geng L: Natural history of infections with high-risk HPV in Chinese women with abnormal cervical cytology findings at baseline. Int J Gynaecol Obstet 110: 137-140, 2010.

16. Castle PE, Walker JL, Schiffman M and Wheeler CM: Hormonal contraceptive use, pregnancy and parity and the risk of cervical intraepithelial neoplasia 3 among oncogenic HPV DNA-positive women with equivocal or mildly abnormal cytology. Int $\mathrm{J}$ Cancer 117: 1007-1012, 2005.

17. Zheng X: Chinese medicine Paiteling treatment of condyloma acuminatum. The curative effect of 392 cases. China science 15: 28, 2006.

18. Chen Rui ZJ and Liaoqin Ping: The clinical effects of paiteling on Cervical intraepithelial neoplasia grade 1 and 2. Chin J Pract Gynecol Obestet: 3, 2011.

19. Tang Huagui XH, Wanyu, Xie Yane and Liu Xuefeng, Ou 2007 The Significance of Prognosis in different age groups eliminated CIN after Leep treatment by detection of HPV. J Hunan Norm Univ (Medical Sciences) 2007.

20. Rui-zhen Li LW, Changhuai, Zhang Zhihong, Liu Yanqiu, Zhou Leiming and Weng Ruifang, Wu HPV clearance related factors after cervical intraepithelial neoplasia surgery. Chin J Matern Child Health Res 2009: 4, 2009.

21. Alonso I, Torne A, Puig-Tintore LM, Esteve R, Quinto L, Campo E, Pahisa J and Ordi J: Pre- and post-conization high-risk HPV testing predicts residual/recurrent disease in patients treated for CIN 2-3. Gynecol Oncol 103: 631-636, 2006.

22. Kim YT, Lee JM, Hur SY, Cho CH, Kim YT, Kim SC and Kang SB: Clearance of human papillomavirus infection after successful conization in patients with cervical intraepithelial neoplasia. Int J Cancer 126: 1903-1909, 2010.

23. Yuquan ZMMXZ: Recent residual or recrudescent development of CIN after surgical cone. Chin J Clin Oncol 34: 3, 2007.

24. Nagai Y, Maehama T, Asato T and Kanazawa K, Persistence of human papillomavirus infection after therapeutic conization for CIN 3: Is it an alarm for disease recurrence? Gynecol Oncol 79: 294-299, 2000

25. Guo-Qin H: Clinical observation of paiteling on treatment of cervicitis combined with high-risk HPV infection. Chin J Woman Child Health Res 23: 3, 2012.

26. Rositch AF, Koshiol J, Hudgens MG, Razzaghi H, Backes DM, Pimenta JM, Franco EL, Poole C and Smith JS: Patterns of persistent genital human papillomavirus infection among women worldwide: A literature review and meta-analysis. Int J Cancer 133: 1271-1285, 2013.

27. Dong H, Liu Y, Tang Y and Liang F: Research on the circumstance of human papillomavirus gene subtypes changing into negativity. J Mol Diagn Therapy 4: 3, 2012 (In Chinese). 